\title{
Neutral density map of Hall thruster plume expansion in a vacuum chamber
}

\author{
Mitchell L. R. Walker ${ }^{\mathrm{a})}$ and Alec D. Gallimore ${ }^{\mathrm{b})}$ \\ Department of Aerospace Engineering, University of Michigan, Ann Arbor, Michigan 48109
}

(Received 9 May 2004; accepted 24 March 2005; published online 29 April 2005)

\begin{abstract}
A neutral background pressure map of the large vacuum test facility (LVTF) is presented. The LVTF is mapped at cold anode flow rates of 5.25, 10.46, and $14.09 \mathrm{mg} / \mathrm{s}$. In addition, neutral background pressure maps are created at hot anode (i.e., discharge on) flow rates of 5.25 and $10.46 \mathrm{mg} / \mathrm{s}$ for discharge voltages of 300 and $500 \mathrm{~V}$, corresponding to P5 Hall thruster operating conditions ranging from 1.5 to $5.0 \mathrm{~kW}$. The chamber pressure is mapped at nominal xenon pumping speeds of 140000 and $240000 \mathrm{l} / \mathrm{s}$. The pressure map is performed with a rake consisting of five calibrated BayardAlpert hot-cathode ionization gauges. The plume expansion appears to be independent of anode flow rate and facility background pressure. Analysis of axial pressure profiles on the LVTF's centerline shows that the plume pressure decreases from a maximum at the thruster exit plane down to the facility background pressure at approximately $2 \mathrm{~m}$ downstream of the exit plane. Comparison of axial pressure profiles on the LVTF's centerline shows that the neutral density is nearly the same for cold flow and hot flow. The study shows that a cold flow neutral density background map accurately characterizes the neutral density in an operating Hall thruster plume. () 2005 American Institute of Physics. [DOI: 10.1063/1.1915011]
\end{abstract}

\section{INTRODUCTION}

To create the on-orbit environment in a ground-based laboratory facility is technically challenging and expensive. All ground-based vacuum facilities possess a low-density background neutral gas due to physical pumping limitations and the leak rate of the facility. As gaseous propellant enters the vacuum chamber, the background pressure rises until the pumping speed, facility leak rate, and propellant flow rate equilibrate for the operating condition.

The facility background gas present in the vacuum chamber can have a number of undesirable effects on the measurement of Hall thruster performance and plume characteristics. ${ }^{1}$ High-energy exhaust particles interact with the neutral background particles through charge exchange collisions $(\mathrm{CEX}) .^{2}$ In the plume, the effects of CEX products are most evident in the perimeter, where they lead to an increase in the measured current density. Thruster operation and performance are dependent on the background pressure of the facility. ${ }^{3}$ At elevated background pressures, residual gas particles can be entrained into the thruster discharge region, artificially increasing engine thrust. One approach that is routinely applied to correct performance data for ingested flow is to extrapolate thrust versus pressure data to zero background pressure. ${ }^{4}$ Elevated facility pressure may also alter the ion energy distribution function through elastic collisions between beam ions and neutral background particles. ${ }^{5}$

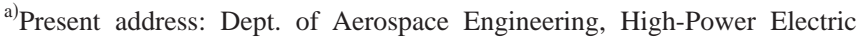
Propulsion Laboratory, 419 Montgomery Knight Building, 270 Ferst Drive, Atlanta, GA 30332; electronic mail: mitchell.walker@ae.gatech.edu

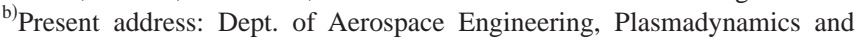
Electric Propulsion Laboratory, 3037 FXB Building, 1320 Beal Ave., Ann Arbor, MI 48109.
}

Due to these effects, the validity of comparisons made between data taken in facilities with different background pressures, especially at $10^{-2} \mathrm{~Pa}\left(10^{-4}\right.$ Torr $)$ and higher, is questionable. ${ }^{6}$ However, comparisons continue to be made between data taken in vacuum chambers with background pressures that differ by orders of magnitude. ${ }^{7}$ In order to correlate data taken in ground-based facilities to in-space thruster performance, the effect of facility background pressure on thruster operation must be fully characterized and taken into account when analyzing test data. Because of the drastic implications of facility effects, electric propulsion technology has reached the point where standard guidelines must be developed for test facilities to ensure reliable engine development and testing. ${ }^{7}$ This need has become even more pressing now that $50 \mathrm{~kW}^{+}$Hall thrusters are being developed. ${ }^{8}$

Several investigations are underway to model thruster performance and the interactions between Hall thruster plumes and spacecraft numerically. ${ }^{9,10}$ The results of these models are highly dependent on the boundary conditions used. For simulations of laboratory experiments, one of the most important auxiliary inputs required by these codes is background pressure of a laboratory vacuum chamber. ${ }^{9}$

To provide high-fidelity data to the models that simulate the interaction between the Hall thruster plume and spacecraft, we must first correct the experimental performance and plume data for facility effects. To this end, the University of Michigan's Plasmadynamics and Electric Propulsion Laboratory (PEPL) has launched an investigation of facility effects introduced by elevated backpressures. This investigation has thus far included measuring the performance of the P5 Hall effect thruster at different pumping speeds, ${ }^{11}$ evaluating a collimated Faraday probe's ability to filter out CEX ions 


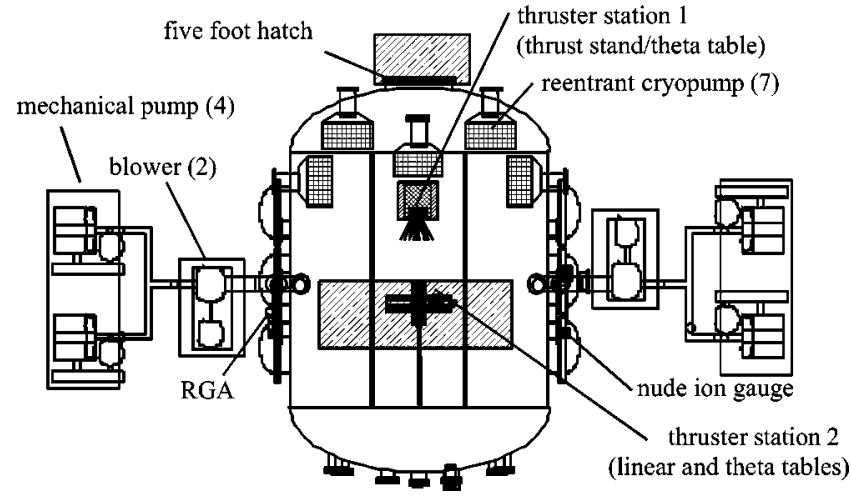

FIG. 1. Schematic of the LVTF.

while measuring the ion current density at elevated back pressures, ${ }^{2,12}$ comparing the performance of multiple nude Faraday probes, ${ }^{13}$ an interrogation of the plasma in the immediate vicinity of the Faraday probe, and mapping the cold flow $^{14}$ pressure of the PEPL's large vacuum test facility (LVTF) and NASA Glenn Research Center's Vacuum Facility 12 in conjunction with a computational facility model using the direct simulation Monte Carlo (DSMC) method to characterize chamber background pressure of the former. ${ }^{15}$ The cold flow pressure map is the first step in creating a technique for making neutral density pressure maps with hot flow in a Hall thruster facility.

To continue development of a tool required to begin to understand and properly correct for facility effects, the neutral gas background pressure of the LVTF is mapped for a series of cold anode flow rates corresponding to Hall thruster operation conditions of $1.5,3.0$, and $9.0 \mathrm{~kW}$, all at $300 \mathrm{~V}$. In addition, the LVTF is mapped at hot anode flow rates of 5.25 and $10.46 \mathrm{mg} / \mathrm{s}$, at $300 \mathrm{~V}$ and $500 \mathrm{~V}$. The objectives of the experiment presented in this article are to demonstrate a technique for making neutral density pressure maps with hot flow in a vacuum facility and to create a technique for calibrating a vacuum chamber in terms of pressure to account for elevated back pressures while testing Hall thrusters. In addition, the data collected aid validation of simulations of the neutral background pressure with the thruster in operation.

\section{EXPERIMENTAL APPARATUS}

\section{A. Vacuum facility}

All experiments are conducted in the LVTF, shown schematically in Fig. 1. The thruster is mounted at thruster station 1. The LVTF is a stainless-steel clad vacuum chamber that has a diameter of $6 \mathrm{~m}$ and a length of $9 \mathrm{~m}$. Two blowers, each with a pumping speed of $940 \mathrm{l} / \mathrm{s}$, and four $190 \mathrm{l} / \mathrm{s}$ mechanical pumps evacuate the LVTF to a moderate vacuum of 4-13 $\mathrm{Pa}$. To reach high vacuum the LVTF is equipped with seven CVI TM-1200 re-entrant cryopumps, each of which is surrounded by a $\mathrm{LN}_{2}$ baffle. The combined pumping speed of the facility is $500000 \mathrm{l} / \mathrm{s}$ on air, and $240000 \mathrm{l} / \mathrm{s}$ on xenon with a base pressure of $2.7 \times 10^{-5} \mathrm{~Pa}\left(2 \times 10^{-7}\right.$ Torr $)$ at the average anode flow rates investigated-5.25, 10.46, and $14.09 \mathrm{mg} / \mathrm{s}$, all with a $0.92 \mathrm{mg} / \mathrm{s}$ cathode flow. At a nominal xenon pumping speed of $240000 \mathrm{l} / \mathrm{s}$, the corresponding operating pressures of the LVTF are approximately 4.5 $\times 10^{-4} \mathrm{~Pa}\left(3.4 \times 10^{-6}\right.$ Torr $), 6.9 \times 10^{-4} \mathrm{~Pa}\left(5.2 \times 10^{-6}\right.$ Torr $)$, and $8.8 \times 10^{-4} \mathrm{~Pa}\left(6.6 \times 10^{-6}\right.$ Torr $)$ on xenon.

Chamber pressure is monitored by a hot-cathode ionization gauge, as indicated in Fig. 1. The gauge is a Varian model ultrahigh vacuum (UHV)-24 nude gauge with a Varian UHV senTorr vacuum gauge controller. The UHV-24 nude gauge is calibrated for air by the manufacturer. Pressure measurements from the gauge are corrected for xenon using the known base pressure on air and a correction factor of 2.87 for xenon according to the following equation: ${ }^{16}$

$$
P_{c}=\frac{P_{i}-P_{b}}{2.87}+P_{b},
$$

where $P_{c}$ is the corrected pressure on xenon, $P_{b}$ is the base pressure, and $P_{i}$ is the indicated pressure when xenon is flowing into the vacuum chamber.

Table I shows the LVTF operating pressure for each flow rate at the nominal xenon pumping speeds of 140000 and $2400001 / \mathrm{s}$. A previous study shows that the nude gauge reading is a good estimate of the true chamber pressure. ${ }^{15}$ The chamber pressures listed in Table I are from the nude gauge and are corrected for xenon.

TABLE I. Nominal pumping speeds and corresponding LVTF operating pressures for each anode flow rate and thruster condition investigated.

\begin{tabular}{ccccccc}
\hline \hline $\begin{array}{c}\text { Discharge } \\
\text { voltage } \\
(\mathrm{V})\end{array}$ & $\begin{array}{c}\text { Discharge } \\
\text { current } \\
(\mathrm{A})\end{array}$ & $\begin{array}{c}\text { Anode } \\
\text { flow } \\
(\mathrm{mg} / \mathrm{s})\end{array}$ & $\begin{array}{c}\text { Cathode } \\
\text { flow } \\
(\mathrm{mg} / \mathrm{s})\end{array}$ & $\begin{array}{c}\text { Nominal } \\
\text { pumping } \\
\text { speed } \\
(\mathrm{l} / \mathrm{s})\end{array}$ & $\begin{array}{c}\text { Chamber } \\
\text { pressure } \\
\text { (nude) } \\
(\text { Torr Xe) }\end{array}$ & $\begin{array}{c}\text { Chamber } \\
\text { pressure } \\
\text { (nude) } \\
(\mathrm{Pa} \mathrm{Xe})\end{array}$ \\
\hline 300 & 4.88 & 5.25 & 0.92 & 140000 & $5.7 E-06$ & $7.6 E-04$ \\
500 & 5.30 & 5.25 & 0.92 & 140000 & $5.7 E-06$ & $7.6 E-04$ \\
- & - & 5.25 & 0.92 & 140000 & $5.7 E-06$ & $7.6 E-04$ \\
- & - & 10.46 & 0.92 & 140000 & $8.4 E-06$ & $1.1 E-03$ \\
- & - & 14.09 & 0.92 & 140000 & $1.1 E-05$ & $1.5 E-03$ \\
300 & 4.80 & 5.25 & 0.92 & 240000 & $3.5 E-06$ & $4.7 E-04$ \\
500 & 5.22 & 5.25 & 0.92 & 240000 & $3.4 E-06$ & $4.5 E-04$ \\
- & - & 5.25 & 0.92 & 240000 & $3.4 E-06$ & $4.5 E-04$ \\
- & - & 10.46 & 0.92 & 240000 & $5.2 E-06$ & $6.9 E-04$ \\
- & - & 14.09 & 0.92 & 240000 & $6.6 E-06$ & $8.8 E-04$ \\
\hline \hline
\end{tabular}




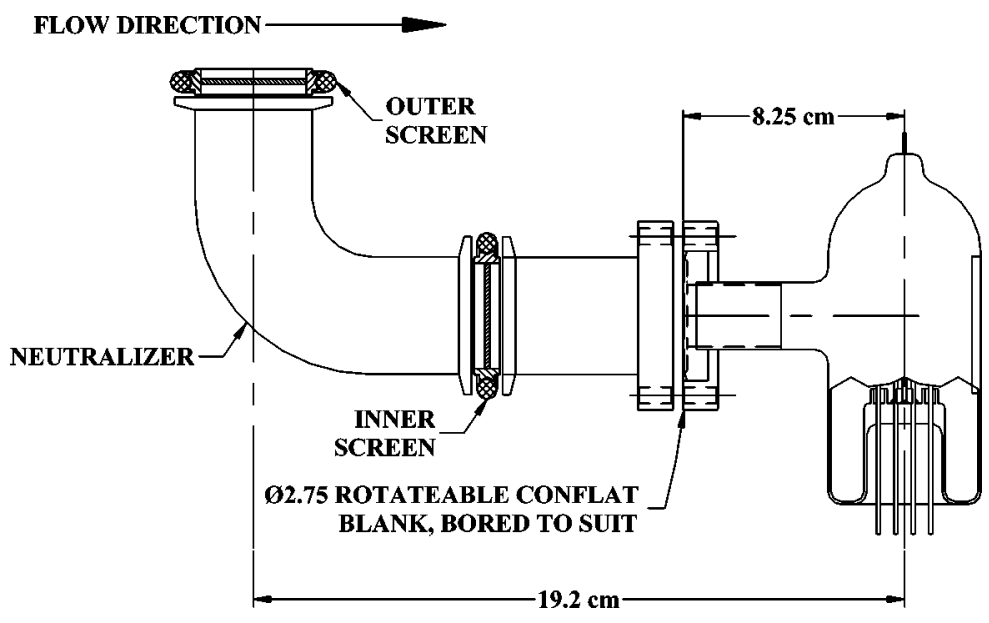

FIG. 2. Schematic of the Varian 571 BA 1onization gauge connected to the neutralizer.

\section{B. Hall thruster}

All experiments are performed on the AFRL/UM P5 laboratory-model Hall thruster. The P5 has a mean diameter of $148 \mathrm{~mm}$, a channel width of $25 \mathrm{~mm}$, a channel depth of $38 \mathrm{~mm}$, and a nominal power rating of $5 \mathrm{~kW} .{ }^{17}$ A more detailed description of the $\mathrm{P} 5$ can be found in Ref. 17. $\mathrm{A} \mathrm{LaB}_{6}$ laboratory-model hollow cathode is located at the 12 o'clock position on the thruster. The cathode orifice is located approximately $30 \mathrm{~mm}$ downstream from the outer front pole piece.

High-purity (99.9995\% pure) xenon propellant is supplied to the Hall thruster from compressed gas bottles through stainless-steel feed lines. MKS 1179JA mass flow controllers meter the anode and cathode propellant flows. The flow controllers are calibrated with a custom apparatus that measures gas pressure and temperature as a function of time in an evacuated chamber of known volume. The mass flow controllers have an accuracy of $\pm 1 \%$ full scale.

\section{Ionization gauge}

The Bayard-Alpert (BA) hot-cathode ionization gauge measures pressure over the range of $10^{-2} \mathrm{~Pa}\left(10^{-4}\right.$ Torr $)$ to $10^{-10} \mathrm{~Pa}\left(10^{-12}\right.$ Torr $)$ with an accuracy of $\pm 20 \%$ as reported by Varian. ${ }^{18}$ Estimates of the pressure for the experiment are $10^{-3} \mathrm{~Pa}\left(10^{-5}\right.$ Torr $)-10^{-6} \mathrm{~Pa}\left(10^{-8}\right.$ Torr), based on previous experimental data taken by the wall gauges. Because of its accuracy over the anticipated range of pressures, the BA gauge is chosen to measure the chamber pressure field for the cold and hot flow pressure maps.

Five Varian 571 BA type standard range ionization gauge tubes measure the chamber pressure field in the LVTF. Pressure maps of the chamber are taken with xenon gas flowing through the anode and cathode with and without the thruster discharge. Thus, the BA gauges need a neutralizer to ensure that the plasma does not affect the pressure measurements. To make the hot and cold flow experiments identical in setup, the neutralizers are also used during the cold flow experiment. The neutralizer design prevents plume ions from having a direct line of sight to the ionization gauge filament. The neutralizer contains two 72 mesh screens $(0.5 \mathrm{~mm}$ by $0.5 \mathrm{~mm}$ and $1.0 \mathrm{~mm}$ thick) that are floating to ensure neutralization of any ions that travel inside the orifice that are not neutralized by the grounded walls of the neutralizer body.
Figure 2 shows the Varian 571 BA ionization gauge and the neutralizer along with their orientation with respect to the anode flow direction.

The screen grid openings are sized to ensure that the sheaths merge at all locations within the exhaust plume. A grid opening larger than a few Debye lengths will not allow the sheaths to merge. Therefore, repulsion of beam ions will not occur near the grid opening centerline, which allows beams ions to travel into the ionization gauge and be collected by the filament. The Debye length is calculated with data previously taken in the P5 plume using a Langmuir probe. The electron number density $\mathrm{n}_{\mathrm{e}}$ and electron temperature $\mathrm{T}_{\mathrm{e}}$ are approximately $7.5 \times 10^{10} \mathrm{~cm}^{-3}$ and $1.6 \mathrm{eV}$ at a location $1 \mathrm{~m}$ downstream of the P5 exit plane. ${ }^{17}$ This yields a Debye length of $0.034 \mathrm{~mm}$. The screen opening is $0.5 \mathrm{~mm}$ by $0.5 \mathrm{~mm}$, which requires a sheath thickness of approximately 7 Debye lengths for the sheaths to merge. Away from the thruster centerline and exit plane, the Debye length increases due to the decrease in electron number density. A longer Debye length ensures that the sheaths have merged, which makes it less likely for ions to enter the gauge. Thus, the ion filter is more effective the farther the gauge is from the thruster exit plane and from thruster centerline.

The outer screen of the neutralizer, located in the horizontal plane of the chamber centerline, is in direct contact with the plasma for the hot flow pressure maps. To avoid disturbing the ionization gauge pressure measurements, the outer screen is electrically isolated from the rest of the neutralizer, so that the screen floats. A bias voltage study on the outer screen, presented in a later section, validates this configuration. In addition, an identical inner screen is placed near the entrance of the ionization gauges. The inner screen is also electrically isolated from the neutralizer structure.

\section{Ionization gauge calibration}

Calibration of the five ionization gauge systems is performed by the Helium Leak Testing Incorporated Calibration Laboratory. Two of the BA gauges are controlled by separate Varian senTorr gauge controllers. The remaining three BA gauges are controlled by a Varian multigauge controller. Each system, comprised of a BA gauge, the actual internal and external cables used in the LVTF, a Varian ten-wire vacuum chamber instrumentation feedthrough, and a Varian 


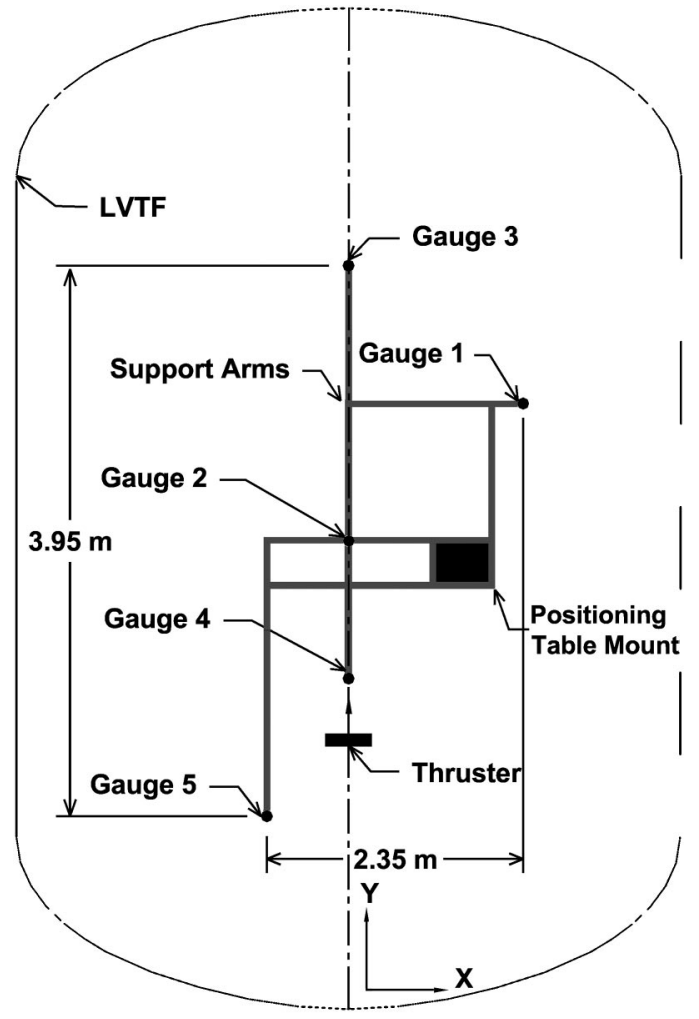

FIG. 3. Schematic of the IGPS mounted in the LVTF.

BA circuit board mounted in either the senTorr or multigauge controller, is calibrated with xenon as a one-piece unit using a National Institute of Standards and Technology traceable Leybold-Heraeus Viscovac VM211 spinning rotor viscosity gauge.

\section{E. Ionization gauge positioning system}

To generate the two-dimensional pressure map inside the LVTF, the ionization gauges are mounted to a custom built, two-axis positioning stage composed of a $1.8 \mathrm{~m}$ long linear stage in the radial direction that is mounted on a $0.9 \mathrm{~m}$ long linear stage in the axial direction, both with an absolute linear position accuracy of $0.15 \mathrm{~mm}$. The ionization gauge positioning system (IGPS) mounts to the positioning stage and carries the five BA gauges used to survey the chamber. Figure 3 shows a schematic of the IGPS mounted within the LVTF. The IGPS allows the pressure measurements to be taken throughout the majority of the chamber with a single evacuation cycle of the LVTF. The locations mapped by the IGPS cover an area with a minimum distance from the thruster of $0.5 \mathrm{~m}$, encompassing the typical $1 \mathrm{~m}$ distance at which plume properties are measured. Pressures at locations closer than $0.5 \mathrm{~m}$ exceed the shut-down limit of the ionization gauge controller.

Figure 4 displays the IGPS mounted in the LVTF and the $25 \mathrm{~cm}$ by $25 \mathrm{~cm}$ square grid on which data points are taken. The solid circles indicate the position of each of the five probes when the IGPS is in the initial position. Gauge 1 is positioned on the opposite side of the chamber centerline to confirm that possible wake effects generated off the gauges do not interfere with downstream probes. Figure 4 also

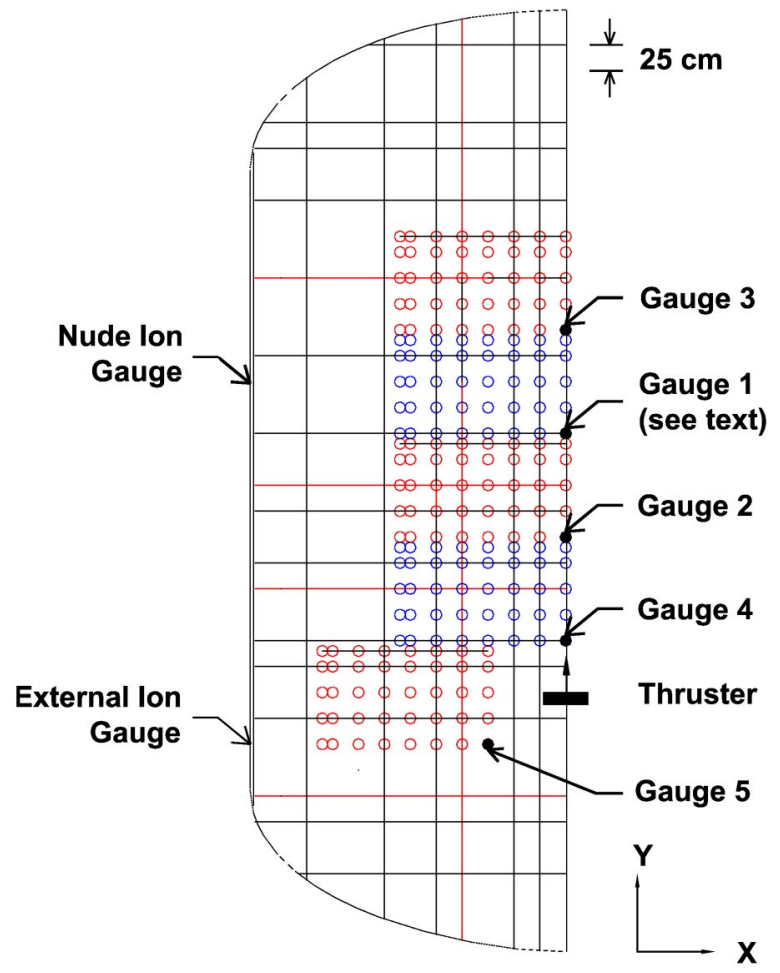

FIG. 4. (Color online) LVTF half-plane (looking down) with the IGPS and a $25 \mathrm{~cm}$ by $25 \mathrm{~cm}$ square grid. Each open circle denotes the location of a data point.

shows the coordinate system used for this experiment. The coordinate system origin is located at the discharge chamber exit plane on the thruster centerline.

\section{EXPERIMENTAL RESULTS}

\section{A. Ionization gauge operation}

To operate the BA gauges on the IGPS, a custom set of cables are constructed. These cables pass through the chamber wall on five, ten-wire instrumentation feedthroughs. The overall cable lengths from controller to BA gauge are between 15 and $23 \mathrm{~m}$, depending on the location of the particular gauge. To verify the operation of each line after the setup is complete, a sealed-glass ionization gauge is operated with a senTorr controller. This test confirms the operation of the equipment while the facility is at atmosphere to avoid unnecessary evacuation cycles of the vacuum chamber. Varian reports that the reference ionization tube is sealed off at less than $6.7 \times 10^{-4} \mathrm{~Pa}\left(5.0 \times 10^{-6}\right.$ Torr $)$. Each of the five ionization gauge systems measure pressures below the maximum pressure reported by the vendor. The maximum spread in measured pressure is $35 \%$, which is the standard uncertainty of BA gauges. The BA gauges mounted to the IGPS measure pressures within $45 \%$ of the pressure reported on the nude gauge used to monitor facility background pressure. This agreement confirms that the ionization gauges mounted on the IGPS are operating properly at vacuum.

We assume that chamber pressure is horizontally symmetric about the chamber centerline in the LVTF. This assumption reduces the number of spatial positions that are mapped. All pressure map data presented are only from one side of the chamber. In a previous experiment we created a 


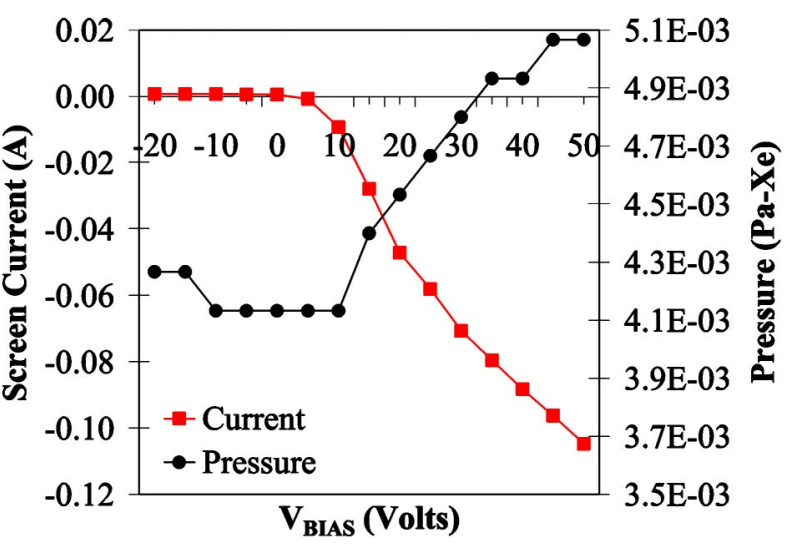

FIG. 5. (Color online) Outer screen bias voltage study.

cold flow pressure map of the LVTF with the same ionization gauges and neutralizers used in the experiments presented in this paper. The results of that study show that the neutralizer conductance does not noticeably affect the time response of the internal ionization gauges. ${ }^{1}$

For the hot flow pressure maps, the BA ionization gauges are immersed in plasma. To characterize the effect of charged particles on the pressure measurements outer and inner screen bias voltage studies are performed using the P5 in the LVTF. The outer and inner screen are electrically isolated from the neutralizer and a biasing wire is connected to each screen so that they can be floated, grounded, or biased to a particular voltage. This configuration allows the screens to repel or attract the charged particle species. The biasing wires connect to a power supply outside of the chamber and current shunts measure the amount of current collected or emitted in each electrical configuration.

First, we investigate the effects of biasing, grounding, and floating the outer and inner screens on the measured pressure to confirm that there is no capacitive coupling between the screens and ionization gauge. This study is performed separately on the inner and outer screen of ionization gauge 2. The results show that with no flow through the thruster the measured pressure is unaffected by floating, grounding, and biasing the inner and outer screens.

Next, an outer screen bias voltage study is performed with the P5 operating at $300 \mathrm{~V}$ and $5.4 \mathrm{~A}$. For this study gauge 2 is monitored at a position $1.5 \mathrm{~m}$ downstream of the thruster exit plane and on the thruster centerline. The gauge pressure and current collected are recorded for each of the electrical configurations. Figure 5 shows the results of the outer screen bias voltage study. Note that the ionization gauge collects ions to determine the pressure. Initially, the outer screen is floated and the pressure measurement is unaffected. In the floating configuration, gauge 2 measures $4.1 \times 10^{-3} \mathrm{~Pa}\left(3.1 \times 10^{-5}\right.$ Torr $)$ and the outer screen collects $0.2 \mathrm{~mA}$. Next, the outer screen is biased from -20 to $50 \mathrm{~V}$ in $5 \mathrm{~V}$ increments. At increasingly negative bias voltages the indicated pressure increases slightly. This may be a result of attracting additional ions into the gauge, which increases the current the gauge filament collects. In the grounded configuration, the indicated pressure is negligibly affected. As the bias voltage becomes increasingly positive, the indicated pressure begins to rise and a large amount of current is collected by the outer screen. The positively biased screen attracts a large number of electrons to the neutralizer, resulting in the increased ionization of neutrals within the gauge. The gauge filament then collects the additional ions, increasing the indicated pressure. This study confirms that floating the outer screen for the hot flow pressure map does not affect the performance of the ionization gauges.

The effects of biasing, grounding, and floating the inner screen on the measured pressure are investigated with the P5 operating at $300 \mathrm{~V}$ and $4.99 \mathrm{~A}$ in the LVTF. In addition, to detect the existence of charged particles within the neutralizer near the entrance to the ionization gauge, an inner screen bias voltage study is performed. For this study gauges 1-5 are monitored in their initial positions as shown in Fig. 4. The gauge pressure and current collected are recorded with the inner screen biased to $+20,-20 \mathrm{~V}$, grounded, and floating. The indicated pressure of each gauge does not change with the electrical configuration. The inner screens of ionization gauges 1,3 , and 5 collect no current for any of the electrical configurations. The inner screen of gauge 4 collected a maximum of $10^{-3} \mathrm{~mA}$ for the $+20 \mathrm{~V}$ bias. The inner screen of gauge 2 collects a maximum of $10^{-4} \mathrm{~mA}$ for the $+20 \mathrm{~V}$ bias. The current due to charge particles entering the neutralizer is far below the $4 \mathrm{~mA}$ emission current of the ionization gauges. Thus, the measured fraction of charged particles entering the ionization gauge during hot flow operation is not large enough to affect the indicated pressure.

The thruster is cycled off and on to observe its effect on the indicated pressure of the ionization gauges. If the ionization gauges truly measure the neutral background pressure, then the neutral pressure measured within $1 \mathrm{~m}$ of the thruster exit plane will be higher for cold flow than with the thruster on. This is because with the thruster on, approximately $80 \%$ of the neutral propellant is ionized and accelerated downstream, reducing the neutral density immediately downstream of the thruster. However, at $1.5 \mathrm{~m}$ downstream of the thruster exit plane and beyond the plume has expanded to the chamber background pressure and the neutral density should not vary with the thruster off or on. The thruster is cycled five times at a power setting of $300 \mathrm{~V}$ and $4.88 \mathrm{~A}$. No appreciable change in indicated pressure is observed $1.5 \mathrm{~m}$ downstream of the exit plane.

\section{B. lonization gauge error}

There are noticeable shifts in the magnitude of the pressure raw data when transitioning between the interrogation area from one ionization gauge to the next. Over the range of motion of each ionization gauge, the change in pressure is smooth. The large gradients between ionization gauges are due to the limited accuracy of the ionization gauge design. No two ionization gauges manufactured indicate the same pressure, even when exposed to the same atmosphere simultaneously.

Using the axial profiles, the raw data are corrected. The raw data of gauge 2 are all shifted by a constant value, so that the most downstream centerline point taken by gauge 4 is approximately equal to the most upstream centerline point taken by gauge 2 . The same procedure is used to correct the 
TABLE II. Ionization gauge correction constants for each pumping speed.

\begin{tabular}{|c|c|c|c|c|c|}
\hline $\begin{array}{c}\text { Gauge } 1 \\
\Delta(\mathrm{Pa}-\mathrm{Xe})\end{array}$ & $\begin{array}{c}\text { Gauge } 2 \\
\Delta(\mathrm{Pa}-\mathrm{Xe})\end{array}$ & $\begin{array}{c}\text { Gauge } 3 \\
\Delta(\mathrm{Pa}-\mathrm{Xe})\end{array}$ & $\begin{array}{c}\text { Gauge } 4 \\
\Delta(\mathrm{Pa}-\mathrm{Xe})\end{array}$ & $\begin{array}{c}\text { Nominal } \\
\text { pumping } \\
\text { speed } \\
(1 / \mathrm{s}\end{array}$ & $\begin{array}{c}\text { Flow } \\
\text { condition }\end{array}$ \\
\hline$+2.7 E-04$ & $+1.3 E-04$ & $-3.2 E-04$ & - & 140000 & Cold \\
\hline$+2.7 E-04$ & $+1.3 E-04$ & $-3.2 E-04$ & $1.3 E-04$ & 140000 & Hot \\
\hline$+2.4 E-04$ & $+1.3 E-04$ & $-2.5 E-04$ & - & 240000 & Cold \\
\hline$+2.4 E-04$ & $+1.3 E-04$ & $-2.5 E-04$ & $1.5 E-04$ & 240000 & Hot \\
\hline
\end{tabular}

data of gauge 1 to gauge 2 and the data of gauge 3 to gauge 1. Thus, individual correction constants are developed for ionizations gauges 1,2 , and 3 . Analysis of the radial profiles shows that the offset between ionization gauge 4 and 5 is on the order of $10^{-5} \mathrm{~Pa}\left(10^{-7}\right.$ Torr $)$. Therefore, a correction constant is not developed for ionization gauge 5 .

The same correction constants for the cold flow data are applied to the hot flow data for gauges 1, 2, and 3 at both 300 and $500 \mathrm{~V}$. Because of the unstable behavior of gauge 5 for hot flow operating conditions, those data are not included in the hot flow analysis. For the hot flow data, an additional correction factor is then needed for gauge 4 . For the hot flow data, the raw data of gauge 4 are all shifted by a constant value so that the most downstream centerline point taken by gauge 4 is approximately equal to the most upstream centerline corrected point taken by gauge 2 .

The chamber was vented to atmosphere between the 140000 and $240000 \mathrm{l} / \mathrm{s}$ pressure maps to repair the radial positioning table. The ionization gauges were exposed to atmosphere and thus one set of correction constants were developed for the $140000 \mathrm{l} / \mathrm{s}$ data and another set are developed for the $240000 \mathrm{l} / \mathrm{s}$ data. Table II shows the correction constants for these data. Figures 6-8 present the corrected cold and hot flow data taken along the chamber centerline.

Figures 9-15 present the cold and hot flow pressure map data recorded in the LVTF. We are unable to acquire data with ionization gauge 5 for the hot flow pressure maps because the pressure in the interrogation area is above the maximum allowable pressure of the controller. Hot flow data for ionization gauge 3 are only available for the $140000 \mathrm{l} / \mathrm{s}$ pumping condition because the controller registers an electrical connection failure whenever the thruster discharge is on for the $240000 \mathrm{l} / \mathrm{s}$ pumping condition. The gauge resumes normal operation when the discharge is extinguished. Inspection of the electrical connections did not locate the problem.

Table I presents the thruster and chamber operating conditions that are investigated and the facility background pressures. The chamber pressure is mapped at cold anode flow rates of $5.25,10.46$, and $14.09 \mathrm{mg} / \mathrm{s}$ for nominal facility pumping speeds of 140000 and $240000 \mathrm{l} / \mathrm{s}$. In addition, the chamber pressure is mapped at the P5 thruster operating conditions of 300 and $500 \mathrm{~V}$ with flow rates of 5.25 and

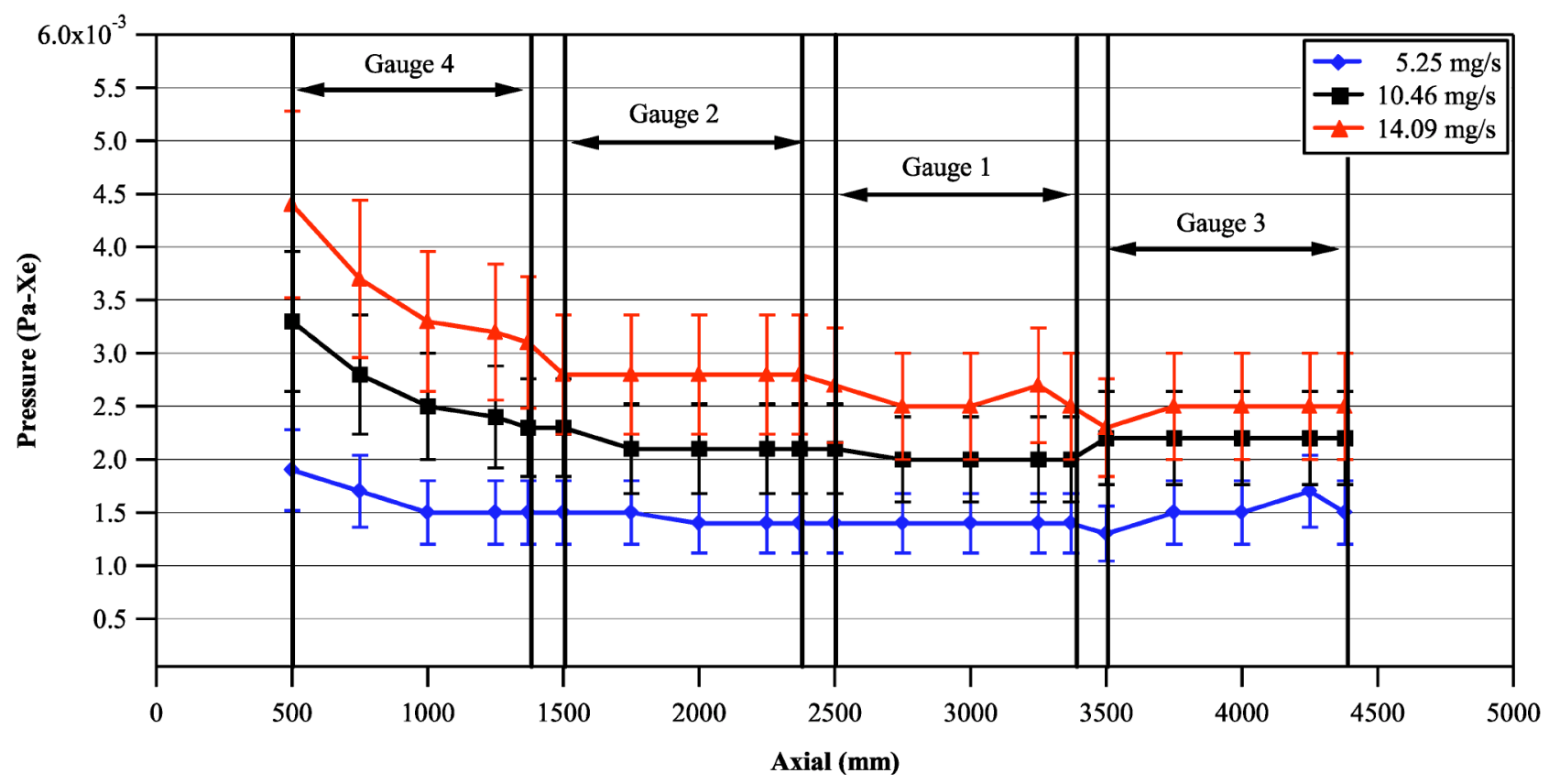

FIG. 6. (Color online) Corrected cold flow data axial profile for a nominal pumping speed of $1400001 / \mathrm{s}$. 


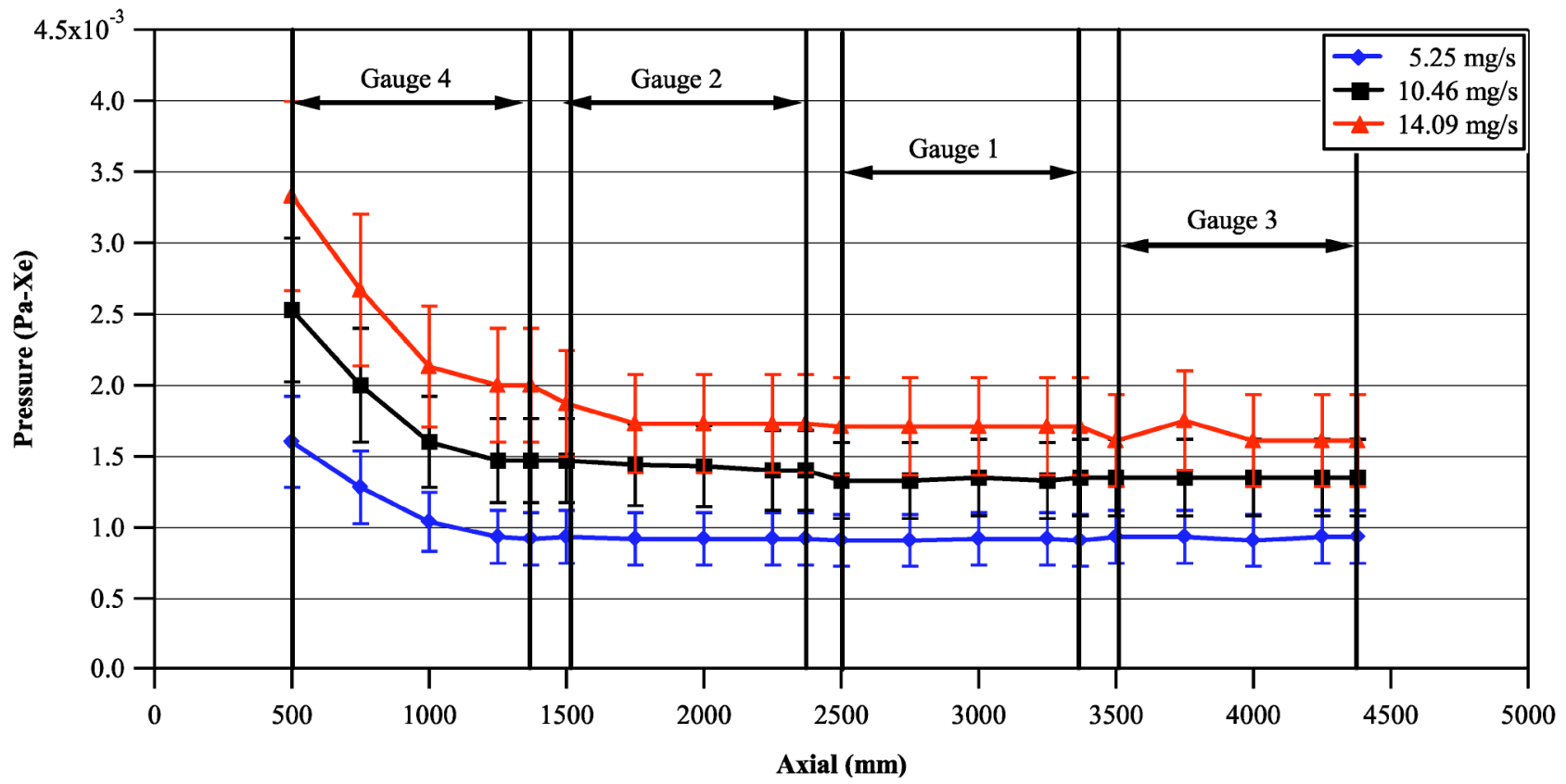

FIG. 7. (Color online) Corrected cold flow data axial profile for a nominal pumping speed of $240000 \mathrm{l} / \mathrm{s}$.

$10.46 \mathrm{mg} / \mathrm{s}$ at nominal facility pumping speeds of 140000 and $240000 \mathrm{l} / \mathrm{s}$.

\section{DISCUSSION}

Analysis of the cold and hot flow axial pressure profiles on the chamber centerline shows that for all flow rates the plume pressure decreases from a maximum at the thruster exit plane to a pressure slightly higher than the facility background pressure approximately $2 \mathrm{~m}$ downstream of the exit plane. As the flow rate increases, the pressure gradient in the plume increases, but the length of the plume expansion to the chamber background pressure remains constant. Increasing the pumping speed lowers the magnitude of the pressure, while the behavior of the axial pressure profile remains unaffected. The previous two trends are apparent in Figs. 6 and 7. The background pressure decreases continually in the radial direction. The trends shown in Figs. 9-15 suggest that the plume background pressure will drop to the facility background pressure near the chamber walls.

The IGPS is used to map the neutral background pressure in Vacuum Facility 12 (VF-12) at NASA Glenn Research Center. The LVTF and VF-12 differ in physical geometry, i.e., the LVTF has a $3 \mathrm{~m}$ larger diameter. Figure 16 shows a cold flow background pressure map in VF-12 with

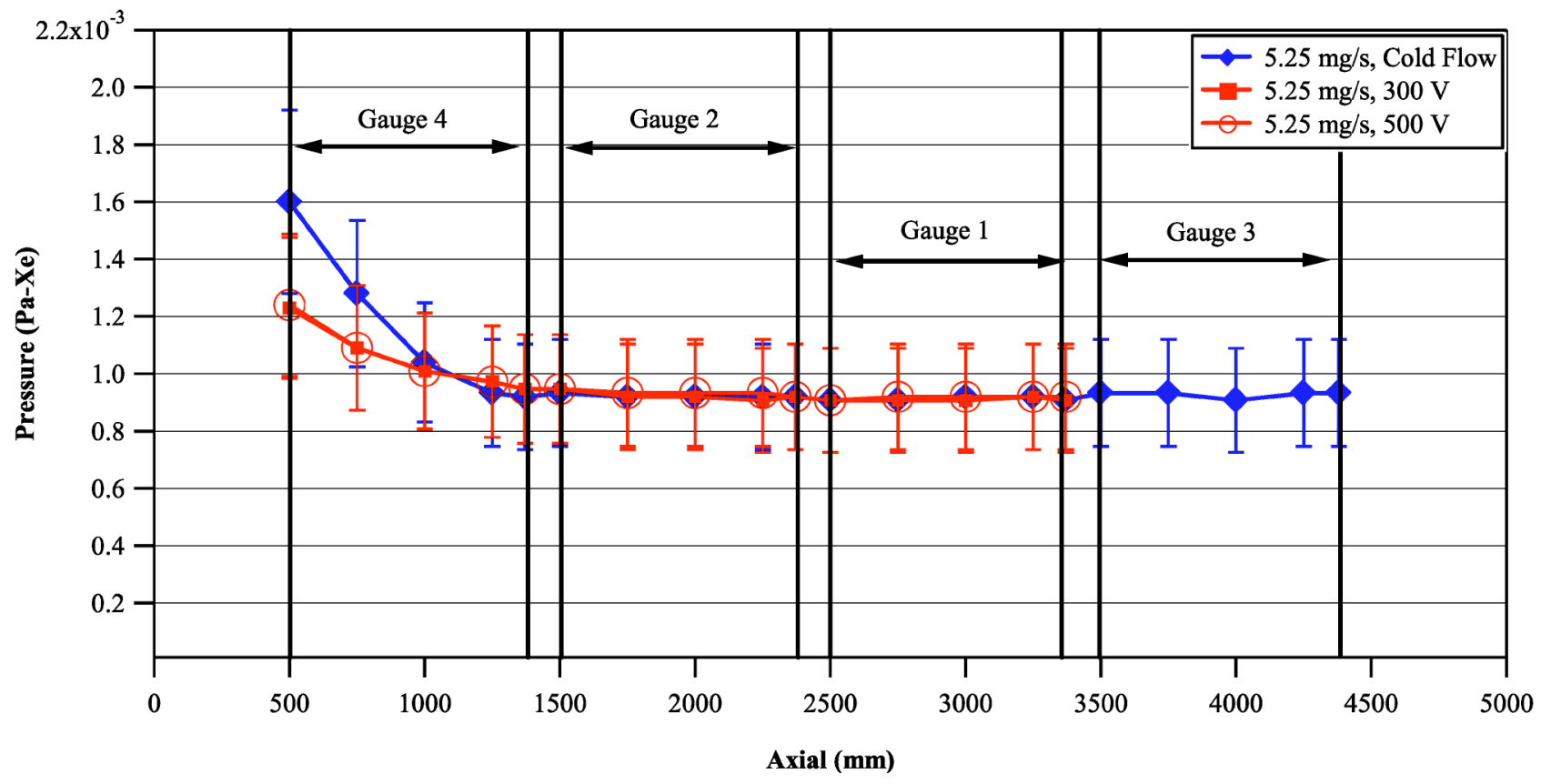

FIG. 8. (Color online) Corrected hot flow data axial profile for a nominal pumping speed of $240000 \mathrm{l} / \mathrm{s}$. 


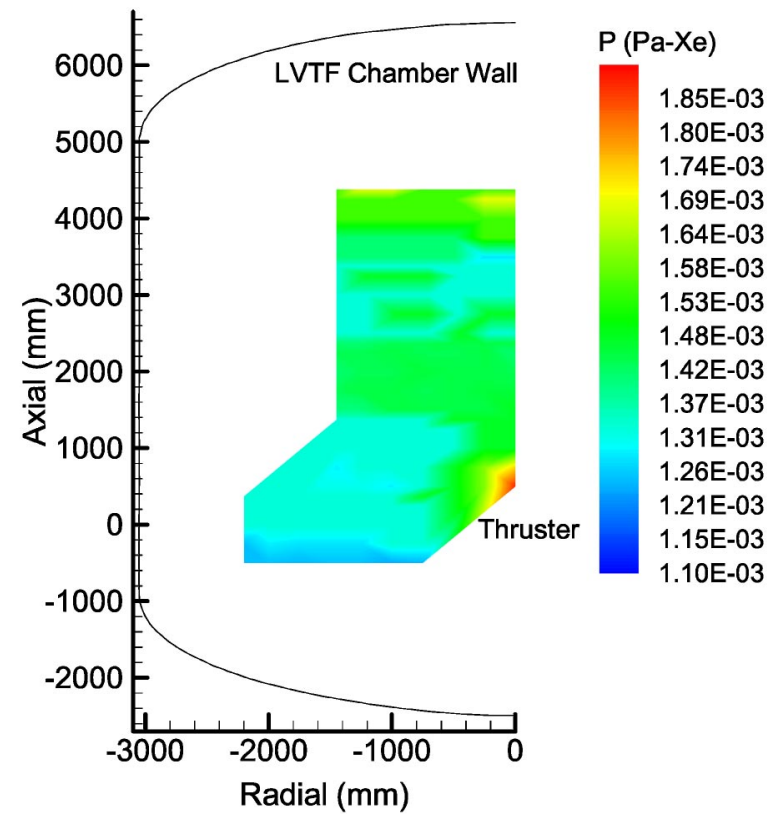

FIG. 9. (Color online) Cold flow pressure map of the LVTF with an anode flow rate of $5.25 \mathrm{mg} / \mathrm{s}$ and a cathode of $0.92 \mathrm{mg} / \mathrm{s}$, at a nominal pumping speed of $140000 \mathrm{l} / \mathrm{s}$ and operating pressure of $6.9 \times 10^{-4} \mathrm{~Pa}(5.2$ $\times 10^{-6}$ Torr), corrected for xenon.

the NASA-173Mv1 at a flow rate of $5.25 \mathrm{mg} / \mathrm{s}$ at an operating pressure of $4.0 \times 10^{-4} \mathrm{~Pa}\left(3.0 \times 10^{-6}\right.$ Torr $) .{ }^{19}$ The background pressure trends in the LVTF are similar to those observed in VF-12.

Figure 8 shows that the far-field axial pressure profiles of the LVTF for hot and cold flow are very close for identical flow rates and pumping speeds. The pressure maps in Figs. 9-11 and Figs. 12-14 show this trend for the 140000 and $240000 \mathrm{l} / \mathrm{s}$ condition, respectively. Figure 15 shows a

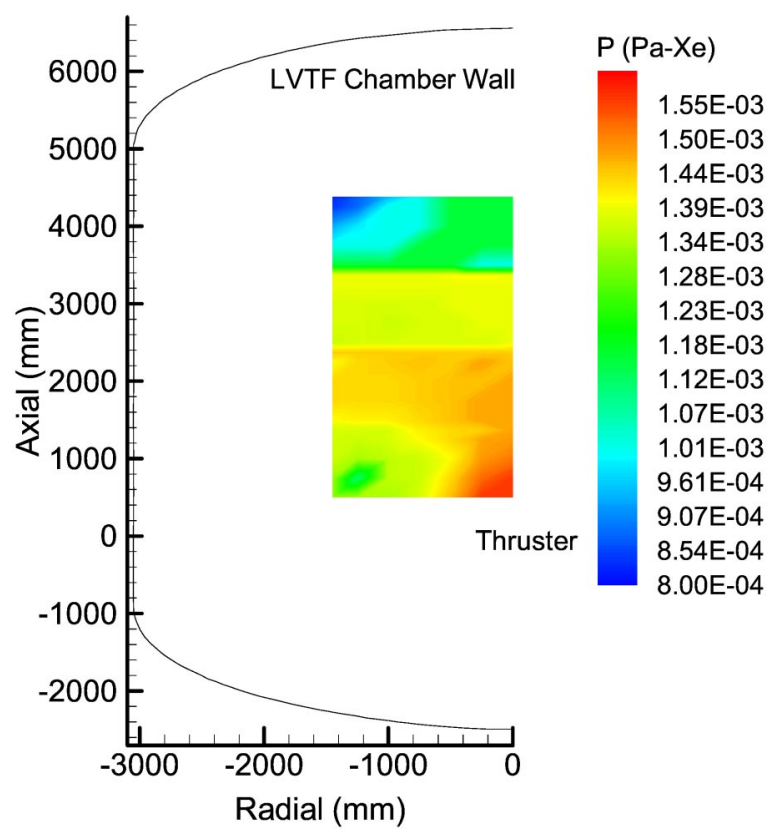

FIG. 10. (Color online) Hot flow pressure map of the LVTF with an anode flow rate of $5.25 \mathrm{mg} / \mathrm{s}$ and a cathode of $0.92 \mathrm{mg} / \mathrm{s}$, at a nominal pumping speed of $140000 \mathrm{l} / \mathrm{s}$ and operating pressure of $7.2 \times 10^{-4} \mathrm{~Pa}$ (5.4 $\times 10^{-6}$ Torr), corrected for xenon. (300 V, $4.88 \mathrm{~A}$ thruster operation).

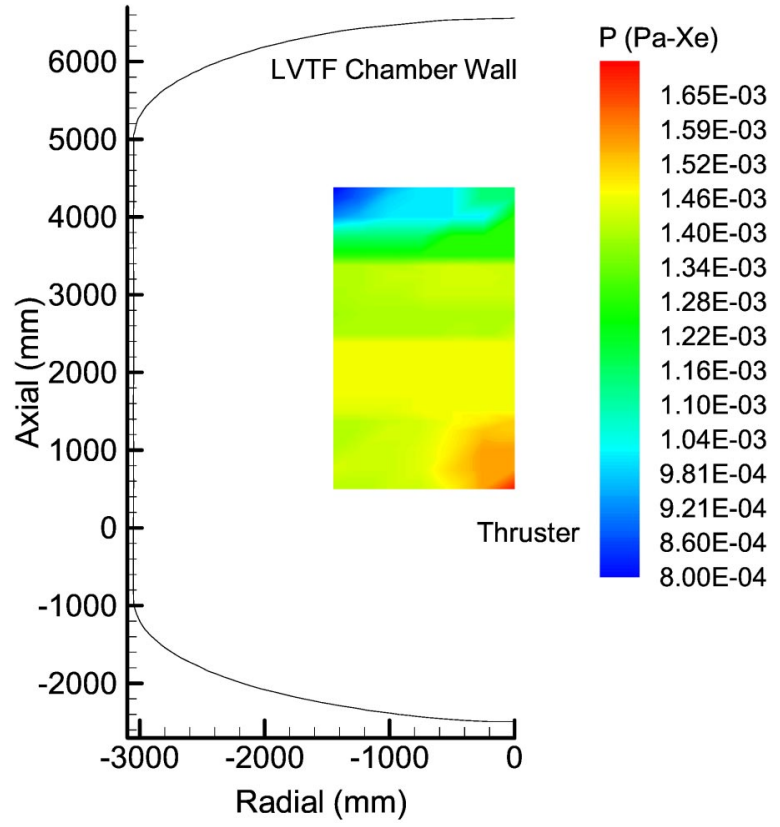

FIG. 11. (Color online) Hot flow pressure map of the LVTF with an anode flow rate of $5.25 \mathrm{mg} / \mathrm{s}$ and a cathode of $0.92 \mathrm{mg} / \mathrm{s}$, at a nominal pumping speed of $140000 \mathrm{l} / \mathrm{s}$ and operating pressure of $7.6 \times 10^{-4} \mathrm{~Pa}$ (5.7 $\times 10^{-6}$ Torr), corrected for xenon $(500 \mathrm{~V}, 5.30 \mathrm{~A}$ thruster operation).

$300 \mathrm{~V}$ hot flow pressure map of the LVTF at an anode flow rate of $10.46 \mathrm{mg} / \mathrm{s}$ and pumping speed of $240000 \mathrm{l} / \mathrm{s}$. The $10.46 \mathrm{mg} / \mathrm{s}$ cold flow pressure map taken at $240000 \mathrm{l} / \mathrm{s}$ is not shown, but is very similar to the $300 \mathrm{~V}, 10.46 \mathrm{mg} / \mathrm{s}$ hot flow pressure map. Thus, measuring the far-field neutral background pressure of the chamber with a cold flow is equivalent to taking the measurement with a hot flow. The backpressure does not decrease by a factor of 4 on thruster centerline for the hot flow cases. This is because the neutral

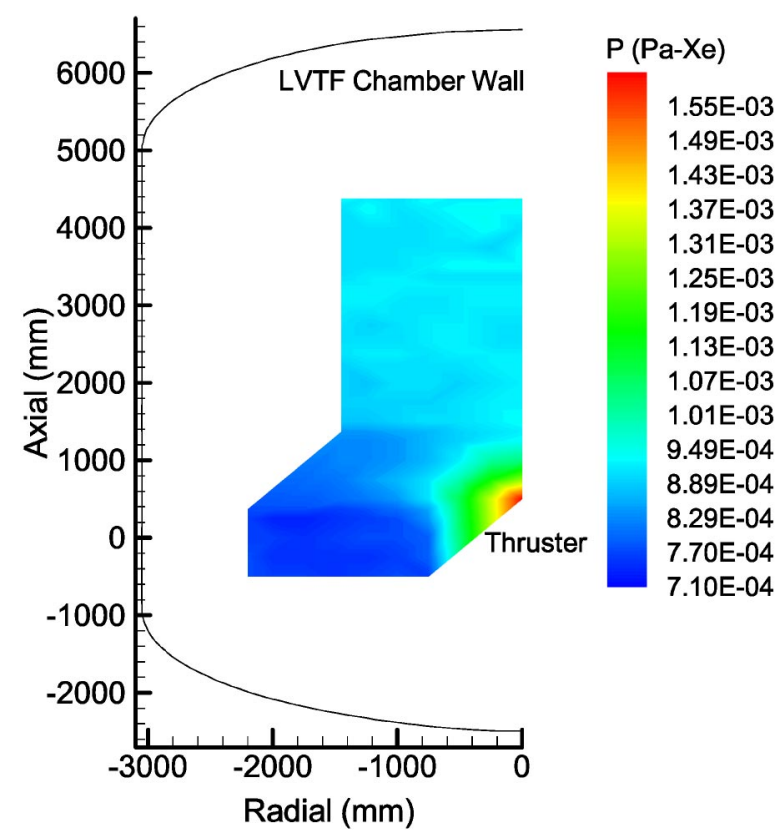

FIG. 12. (Color online) Cold flow pressure map of the LVTF with an anode flow rate of $5.25 \mathrm{mg} / \mathrm{s}$ and a cathode of $0.92 \mathrm{mg} / \mathrm{s}$, at a nominal pumping speed of $240000 \mathrm{l} / \mathrm{s}$ and operating pressure of $4.5 \times 10^{-4} \mathrm{~Pa}(3.4$ $\times 10^{-6}$ Torr), corrected for xenon. 


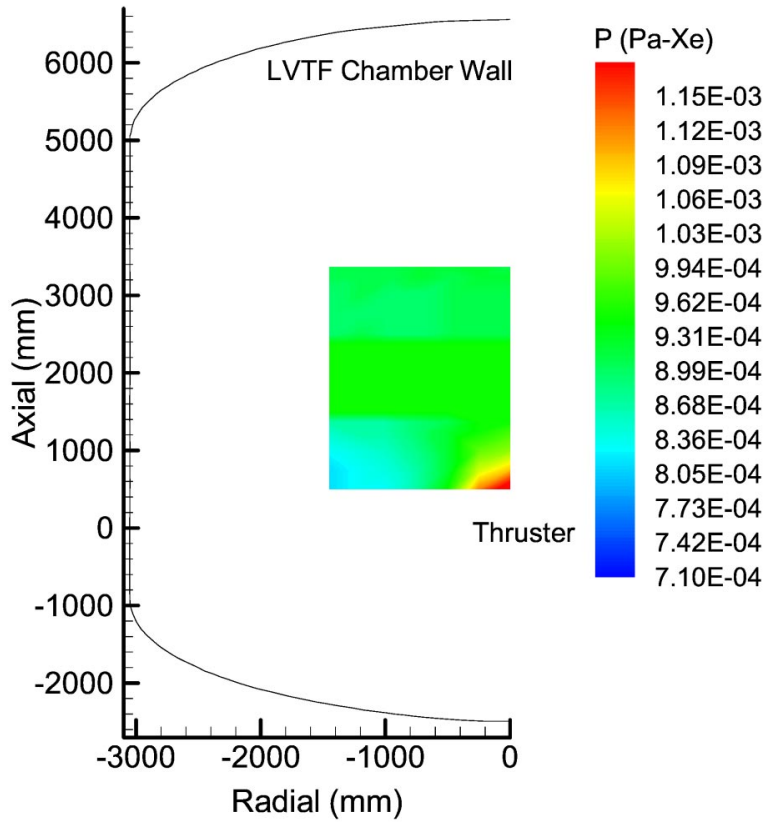

FIG. 13. (Color online) Hot flow pressure map of the LVTF with an anode flow rate of $5.25 \mathrm{mg} / \mathrm{s}$ and a cathode of $0.92 \mathrm{mg} / \mathrm{s}$, at a nominal pumping speed of $240000 \mathrm{l} / \mathrm{s}$ and operating pressure of $4.7 \times 10^{-4} \mathrm{~Pa}(3.5$ $\times 10^{-6}$ Torr), corrected for xenon (300 V, 4.80 A thruster operation).

background gas penetrates the lower density core of the hot flow cases, which increases the measurement of backpressure on thruster centerline.

The fact that the $300 \mathrm{~V}$ hot flow, $500 \mathrm{~V}$ hot flow, and $5.25 \mathrm{mg} / \mathrm{s}$ cold flow axial pressure profiles and background pressures are nearly the same implies that a particle collision with the facility wall reduces the energy of the accelerated plume ion to that of cold flow particle. We also see that the axial pressure profiles and background pressure are nearly

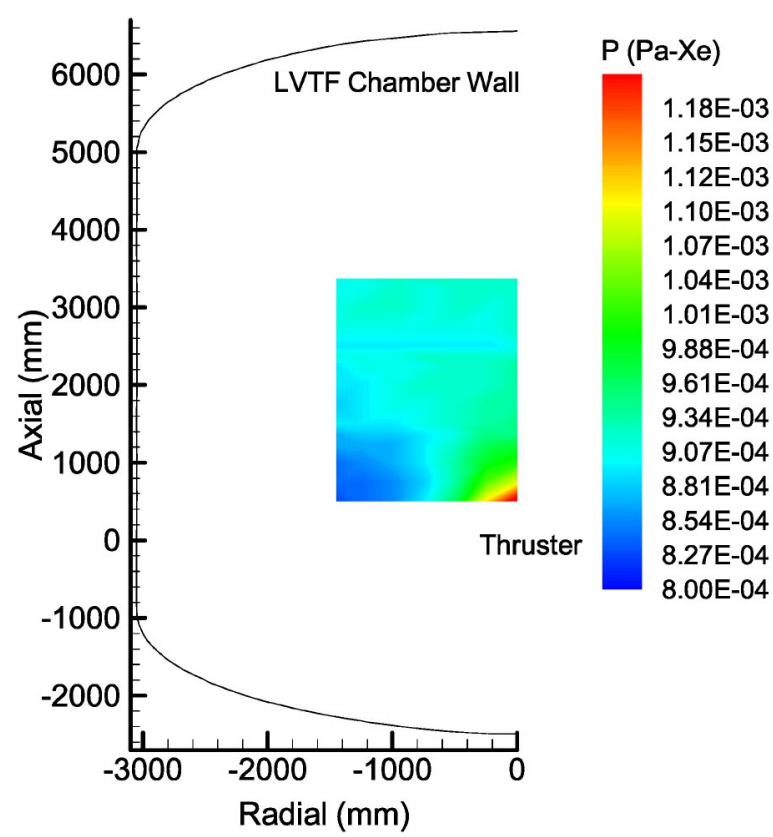

FIG. 14. (Color online) Hot flow pressure map of the LVTF with an anode flow rate of $5.25 \mathrm{mg} / \mathrm{s}$ and a cathode of $0.92 \mathrm{mg} / \mathrm{s}$, at a nominal pumping speed of $240000 \mathrm{l} / \mathrm{s}$ and operating pressure of $4.5 \times 10^{-4} \mathrm{~Pa}(3.4$ $\times 10^{-6}$ Torr), corrected for xenon (500 V, $5.22 \mathrm{~A}$ thruster operation).

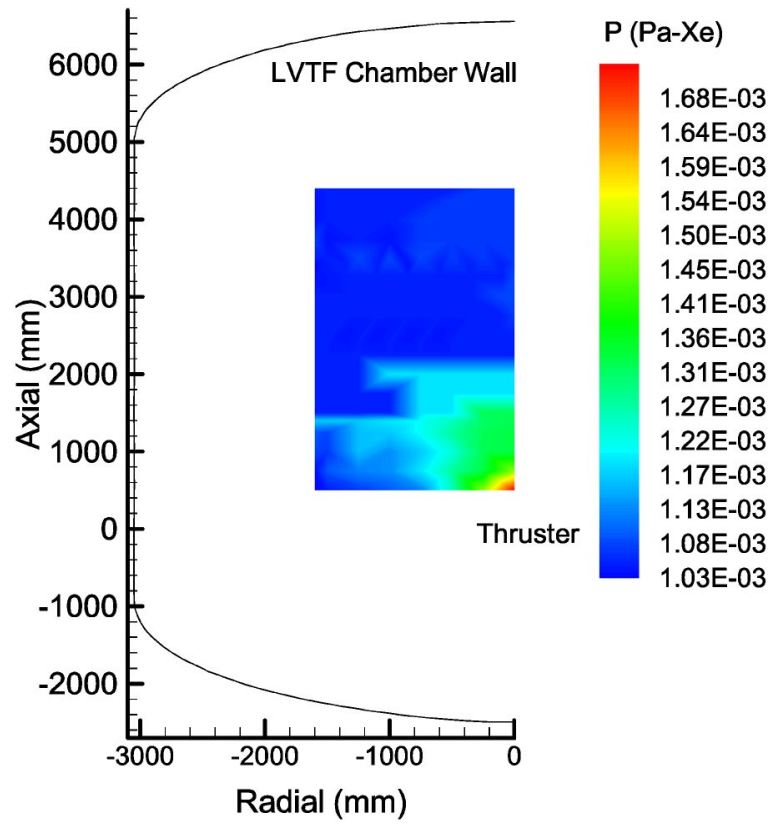

FIG. 15. (Color online) Hot flow pressure map of the LVTF with an anode flow rate of $10.46 \mathrm{mg} / \mathrm{s}$ and a cathode flow rate of $0.60 \mathrm{mg} / \mathrm{s}$, at a nominal pumping speed of $240000 \mathrm{l} / \mathrm{s}$ and operating pressure of $7.6 \times 10^{-4} \mathrm{~Pa}$ $\left(5.7 \times 10^{-6}\right.$ Torr $)$, corrected for xenon $(300 \mathrm{~V}, 11.1 \mathrm{~A}$ thruster operation).

the same for the $10.46 \mathrm{mg} / \mathrm{s}$ cold and hot flow conditions. Therefore, the cryosurface sticking coefficient is unaffected by the hot flow present with the thruster operating.

\section{FACILITY PRESSURE CALIBRATION}

The above experiment demonstrates that the measured pressure field in a vacuum facility due to a cold flow from

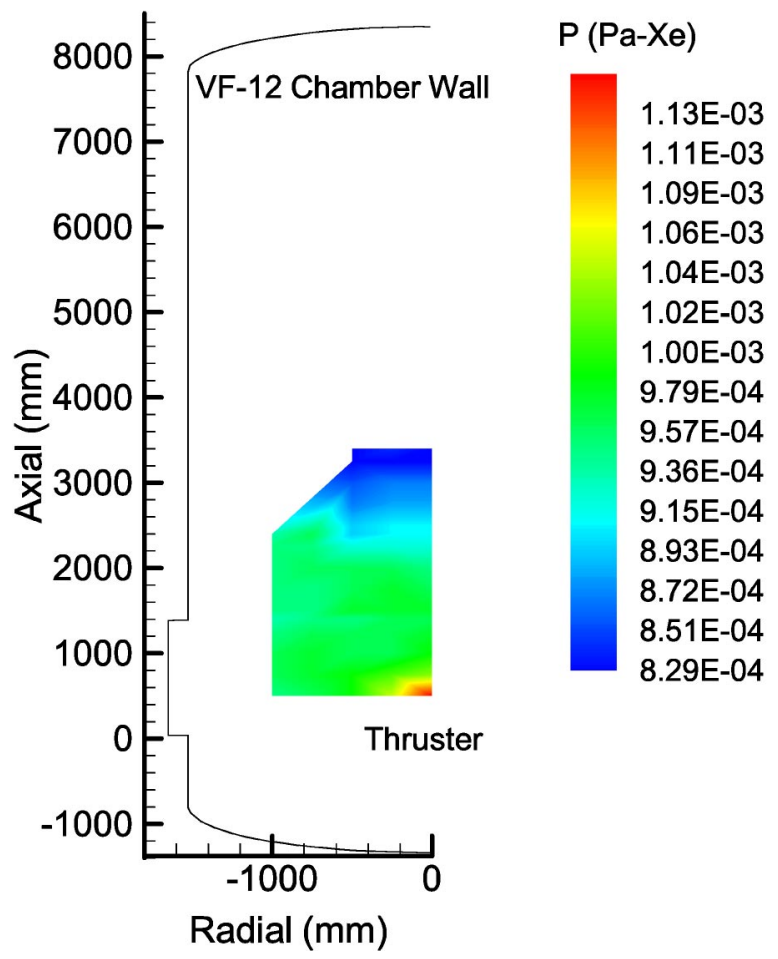

FIG. 16. (Color online) Cold flow pressure map of VF-12 with an anode flow rate of $5.25 \mathrm{mg} / \mathrm{s}$ and a cathode flowrate of $0.60 \mathrm{mg} / \mathrm{s}$, at a nominal pumping speed of $282000 \mathrm{l} / \mathrm{s}$ and operating pressure of $4.0 \times 10^{-4} \mathrm{~Pa}$ $\left(3.0 \times 10^{-6}\right.$ Torr $)$, corrected for xenon. 
the Hall thruster anode and cathode is equivalent to the hot flow condition. This fact simplifies determining the pressure in the vacuum facility containing a Hall thruster plume. With these data we have the ability to calibrate a vacuum facility in terms of pressure.

The measured facility operating pressure at several cold flow rates is used to calibrate a DSMC model of the operating facility. ${ }^{19}$ The numerical model then makes accurate predictions of the backpressure of the vacuum facility for a given propellant flow rate. Simulations of the facility using the numerical model show where on the facility to place an ionization gauge to monitor operating pressure. The simulation results also show any gradients between the wallmounted ionization gauge and the actual backpressure to which the plume expands. Thus, from a measurement of the pressure on the facility wall the true operating pressure at the centerline of the facility is determined.

\section{ACKNOWLEDGMENTS}

The authors would like to thank Robert Jankvosky at NASA Glenn Research Center for his assistance in calibrating the ionization gauges and loaning a hollow cathode. We would also like to thank undergraduate Robert Thomas for his help constructing the IGPS and experimental setup. The experimental research is supported by the Air Force Office of Scientific Research through Grant Nos. F49620-00-1-0201 and F49620-01-1-0061. In addition, Mr. Mitchell Walker is supported by the Michigan Space Grant Consortium and the National Science Foundation.

${ }^{1}$ L. B. King and A. D. Gallimore, Proceedings of the 32nd Joint Propulsion Conference, Lake Buena Vista, FL, July 1-3, 1996, AIAA-96-2712.

${ }^{2}$ R. R. Hofer, M. L. R. Walker, and A. D. Gallimore, Proceedings of the 27th International Electric Propulsion Conference, Pasadena, CA, October 15-19, 2001, IEPC-01-20.

${ }^{3}$ D. H. Manzella and J. M. Sankovic, Proceedings of the 31st Joint Propulsion Conference and Exhibit, San Diego, CA, July 10-12, 1995, AIAA95-2927.
${ }^{4}$ K. H. de Grys, N. Meckel, G. Callis, D. Greisen, A. Hoskins, D. King, F. Wilson, L. Werthman, and V. Khayms, Proceedings of the 27th International Electric Propulsion Center, Pasadena, CA, October 15-19, 2001.

${ }^{5}$ A. D. Gallimore, J. Spacecr. Rockets 38, 441 (2001).

${ }^{6}$ T. Randolph, V. Kim, H. Kaufman, K. Kozubsky, V. V. Zhurin, and M. Day, Proceedings of the 23rd International Electric Propulsion Conference, Seattle, WA, September 13-16, 1993, IEPC-93-093.

${ }^{7}$ A. Semenkin, V. Kim, O. Gorshkov, and R. S. Jankovsky, Proceedings of the 27th International Electric Propulsion Conference, Pasadena, CA, October 15-19, 2001, IEPC-2001-070.

${ }^{8}$ R. S. Jankovsky, D. Jacobson, and D. H. Manzella, Proceedings of the 39th Joint Propulsion Conference and Exhibit, Huntsville, AL, July 2023 , 2003, AIAA-2003-4550.

${ }^{9}$ I. D. Boyd and A. Ketsdever, J. Spacecr. Rockets 38, 381 (2001).

${ }^{10}$ J. M. Fife, W. Hargus Jr., D. A. Jaworske, C. J. Sarmiento, L. Mason, R. S. Jankovsky, J. S. Snyder, S. Malone, J. M. Haas, and A. D. Gallimore, Proceedings of the 36th Joint Propulsion Conference and Exhibit, Huntsville, AL, July 17-19, 2000, AIAA-2000-3521.

${ }^{11}$ R. R. Hofer, P. Y. Peterson, and A. D. Gallimore, Proceedings of the 27th International Electric Propulsion Conference, Pasadena, CA, October 1519, 2001, IEPC-01-045.

${ }^{12}$ K. H. de Grys, D. L. Tilley, and R. S. Aadland, Proceedings of the 35th Joint Propulsion Conference and Exhibit, Los Angeles, CA, June 20-24, 1999, AIAA-99-2293.

${ }^{13}$ M. L. R. Walker, R. R. Hofer, and A. D. Gallimore, Proceedings of the 38th Joint Propulsion Conference and Exhibit, Indianapolis, IN, July 7-10, 2002, AIAA-2002-4253.

${ }^{14}$ Throughout the paper, we use the phrase "cold flow" to denote xenon flowing through the thruster anode and cathode without a plasma discharge and "hot flow" to denote xenon flowing through the anode and cathode of a thruster in operation.

${ }^{15}$ M. L. R. Walker, A. D. Gallimore, C. Cai, and I. D. Boyd, Proceedings of the 38th Joint Propulsion Conference and Exhibit, Indianapolis, IN, July 7-10, 2002, AIAA-2002-3815.

${ }^{16}$ S. Dushman, Scientific Foundations of Vacuum Technique (Wiley, New York, 1958), Vol. 4.

${ }^{17}$ J. M. Haas, F. S. Gulczinski III, A. D. Gallimore, G. G. Spanjers, and R. A. Spores, Proceedings of the 34th Joint Propulsion Conference and Exhibit, Cleveland, OH, July 12-15, 1998, AIAA-98-3503.

${ }^{18}$ Varian, Vacuum Measurement, Product Catalog, April 152003 〈http:// www.varianinc.com/cgi-bin/nav?products/vacuum/measure/gauges\&cid $=$ JPLHPIHFO $>$

${ }^{19}$ M. L. R. Walker and A. D. Gallimore, Proceedings of the 28th International Electric Propulsion Conference, Toulouse, France, March 17- 21, 2003, IEPC-03-0077. 